\title{
Auditory event-related potentials (ERPs) and mismatch negativity ( MMN) in healthy children and those with attention-deficit or Tourette/ tic symptoms
}

\author{
Robert D. Oades, Alexandra Dittmann-Balcar, Renate Schepker, \\ Christian Eggers, Dieter Zerbin
}

1996 Biological Psychology, 43, 163-185 Published as: doi:10.1016/0301-0511(96)05189-7

RL.HK University Clinic for Child and Adolescent Psychiatry, Pf 1030 43, D-45030 Essen. Germany

\begin{abstract}
:
The study compares 5 auditory event-related potential (ERP) components (PI to P3) after 3 tones differing in pitch and rarity, and contrasts the mismatch negativity (MMN) between them in 12 children with attention-deficit hyperactivity disorder (ADHD, mean 10.2 years of age), 12 healthy controls pair-wise matched for age (controls), and 10 with Chronic Tic or Tourette Syndrome (TS).

Topographic recordings were derived from 19 scalp electrodes. Four major effects are reported. (a) Shorter latencies in ADHD patients were evident as early as 100 ms. (b) Both ADHD and TS groups showed very large P2 components where the maxima were shifted anteriorly. The differences in the later potentials were of a topographical nature.

(c) Frontal MMN was non-significantly larger in the ADHD group but normalized data showed a left rather than a right frontal bias as in control subjects. Maxima for TS were usually posterior. (d) ADHD patients did not show the usual right-biased P3 asymmetry nor the frontal versus parietal P3 latency difference.

From these results it is suggested that ADHD patients process perceptual information faster from an early stage (N1). Further, along with the TS group, ADHD patients showed an unusually marked inhibitory phase in processing (P2), interpreted as a reduction of the normal controls on further processing. Later indices of stimulus processing (N2-P3) showed a frontal impairment in TS and a right hemisphere impairment in ADHD patients. These are interpreted in terms of the difficulties in sustaining attention experienced by both ADHD and TS patients.
\end{abstract}

Keywords: Topography; Event-related potentials; Mismatch negativity; ADHD; Tourette syndrome; Attention

\section{I ntroduction}

Attention, described as the selective aspect of perception (Treisman, 1969), has often been measured in a choice reaction-time or continuous performance task where a response is required to one of several types of stimulus presented in sequence. Children with attention-deficit hyperactivity disorder (ADHD) are often impaired on visual (Corkum \& Siegel, 1993) and auditory forms of this task (Satterfield, Schell \& Nicholas, 1994).

We planned to record event-related potentials (ERPs) elicited by tones in an oddball task to examine these indicators of information processing topographically. A 3-tone task (one standard and two deviants) was chosen in order to control for the potentially different processing of pitch and rarity information
(Oades, Walker, Geffen \& Stem, 1988). Such stimulus features are confounded in the 2-tone paradigm (Breton, Ritter, Simson \& Vaughan, 1988) and may indeed be differentially represented in the central nervous system (see Giard, Lavikainen, Reinikainen, Perrin, Bertrand, Pernier \& Näätänen, 1995 on the mismatch negativity (MMN)).

Our subjects were children from the age of 8 years. After testing 12 with symptoms of attention deficit (ADHD), only 6 were found to discriminate above chance levels: only one 8-y-old control failed. ADHD subjects were able to reach an $80 \%$ discrimination between deviant tones from about 10.3 years of age. (Although this did not reflect peripheral stimulus processing abilities (see section 2 , Methods) the possibility of a 'central 
auditory processing' deficit (Cook, Mausbach, Burd, Gascon, Patterson, Johnson, Hankey \& Reynolds, 1993), that remediated, cannot be ruled out entirely.) Indeed, the phenomenon of an impairment that disappeared over 2 years recalls features not only of a short attention span, but a slowness of learning attributed to children with ADHD (Cantwell \& Baker, 1992). A developmental delay in the maturation of information processing has been suggested to be of the order of about 2 years in these children (Satterfield \& Braley, 1977). Thus we decided it would be useful to analyse the passive 3-tone oddball data to see if there was evidence for a delay in processing stimulus features, even though a developmental lag has not been found by all studies (Taylor, Voros, Logan \& Malone, 1993).

We were thus curious to see if an ERP analysis, treating the tones independently, would show up group related differences in the non-task presentation of a passive 3-tone oddball and if this would throw light on the apparent developmental delay hindering discrimination in ADHD children. It should be borne in mind that selection of stimuli for processing not only follows instruction but can occur automatically according to features such as pitch and rarity of presentation (automatic attention). The passive paradigm used here may have incurred 'diffuse' attention in the sense that there was no current task to focus processing resources. This situation has been contrasted with the focused selective attention required in a task situation which has separate effects on ERP measures in healthy subjects (Oades, 1995; Oades, Dittmann-Balcar \& Zerbin, 1995a; Paavilainen, Tiitinen, Alho \& Näätänen, 1993).

Particularly useful in the study of automatic attention-related processes is an index of the registration of the perceptual difference that can be obtained from the difference waveform, (difference waveform; deviant ERP minus standard ERP waveform). The difference waveform is indicative of comparator function and the best known component in it is the mismatch negat-ivity (MMN) with an N1- or N2-like peak latency in the $100-250 \mathrm{~ms}$ range. MMN is a negative-going electrical brain response elicited by any discriminable change in a repetitive sound. It is claimed to be a neuronal trace (working or echoic memory) that precisely en-codes the difference between the physical stimulus characteristics (e.g., frequency, intensity or duration) represented in sensory memory (Giard et al., 1995). It was hypothesized that MMN and the amplitude of the ERP components contributing to MMN would be reduced if there was a fundamental impairment of function leading to impaired discrimin-ation in ADHD children and that an alter-ed topographic distribution of the comp-onents would reflect a maturational delay.

Cognitive (Piaget, 1952) and especially frontal function (Levin, Culhane, Hartmann, Evankovich, Mattson, Ringholz, Ewing-Cobbs \& Fletcher, 1991) continues to develop through $12-16$ y of age. Anatomical maturation of temporal lobe structures also continues into young adulthood (Benes, Turtle, Khan \& Farol, 1994). Topographic recordings are useful for following such maturational changes by marking the approximate locus of activity related to stimulus selection (e.g., frontal versus temporal; Oades, Dittmann-Balcar \& Zerbin, 1996). Thus, an unusual distribution of ERP activity would be predicted from electrodes over frontal and temporal areas of putatively retarded individuals, and hence in ADHD patients. However, only Satterfield and colleagues (Satterfield, Schell, Nicholas 8c Backs, 1988) have reported on the topography of these components in ADHD children and with Winsberg, Javitt, Silipo and Doneshka (1993) described difference waveforms. They reported that frontal processing negativity (target minus non-target ERP) was decreased while MMN seemed to be increased in ADHD patients.

With respect to other ERP markers of stimulus processing in ADHD children, $\mathrm{N} 1$ and $\mathrm{P} 3$ peaks after targets (but not non-targets) are reported to be smaller in both visual and auditory paradigms (Klorman, Salzman, Bauer, Coons, Borgstedt \& Halpem, 1983; Loiselle, Stamm, Maitinsky \& Whipple, 1980; Picton, Donchin, Ford, Kahneman \& 
Norman, 1984). The latency of P3 (Picton et al., 1984) and its frontal P3a and parietal P3b components in a visual paradigm are longer (Taylor et al., 1993). (N1 has been associated with the allocation of resources for processing from the auditory cortex and P3 with updating the associations of the eliciting stimulus, see discussions in: Hansen \& Hillyard, 1980, 1988; Alain, Achim \& Richer, 1993; and Donchin \& Coles 1988, respectively).

Reports differ whether the P2, associated with inhibitory processes (Hegerl \& Juckel, 1993), is smaller or larger in ADHD children (respectively: Satterfield, 1973; Holcomb, Ackerman \& Dykman, 1986). A smaller P2 amplitude might seem compatible with impulsive behaviour commonly associated with ADHD children, if an inhibitory process in the transition from exogenous to endogenous stimulus processing is missing. But we would predict that an increase of P2 amplitude is more consistent with reports of trivial stimuli capturing attention and eliciting response (e.g., task solving strategy in the matching of familiar figures task: Sonuga-Barke, Houlberg \& Hall, 1994; or CPT: Schachar, Tannock, Marriott BE Logan, 1995). This interpretation is an extension of the idea that the 'disfacilitation' aspect of P2 positivity (Schupp, Lutzenberger, Rau \& Birbaumer, 1994) represents inhibition of the competition for processing resources that normally limits further processing of N1 eliciting events. This is consistent with target-related increases of P2 amplitude (Verbaten, Overtoom, Koelega, Swaab-Bameveld, van der Graag, Buitelaar \& van Engeland, 1994) and the proposal of a permissive role for P2-like components even in MMN stimulus evaluation processes (Kofoed, Bak, Rahn \& Saermark, 1995).

But the target-elicited N2, sensitive to the difficulty of a discrimination, is claimed to be smaller in ADHD (Satterfield et al., 1988). This should be reflected in late negative responses to the deviants in view of the putatively impaired effort that ADHD children are reported to bring to bear on stimulus selection (Sonuga-Barke et al., 1994). We are not aware of reports on $\mathrm{P} 1$ in ADHD patients (a component associated with the arrival of information in the cortex) or of relevant studies on children with tics (Tourette Syndrome; TS). TS children were recruited as a comparison group because of the high prevalence of attention-deficit symptoms in TS patients (estimated at 30-500/o; Pauls, Hurst, Kruger, Leckman, Kidd \& Cohen, 1986). However we would expect that if ADHD symptoms were a trait of TS children that, in addition to any special features associated with the syndrome there would be similarities to the ERPs of ADHD children. However if ADHD symptoms were adventitious, then features associated with the primary diagnosis would dominate.

Thus the questions asked are, what is the topographic distribution of ERPs after tones differing in pitch and frequency in the 3 groups of children? The frontotemporal distribution would be predicted to reflect developmental delay (cf. the developmental speech, language and learning delays described for children before the onset of psychosis; Alaghband -Rad, McKenna, Gordon, Albus, Hamburger, Rumsey, Frazier, Lenane \& Rapoport, 1995). Are the ERP indicators of stages of information processing differentially sensitive to stimulus features such as tone frequency and rarity (cf. sensory memory discussed above)? Differences of inhibitory processing would be expected in impulsive subjects (e.g., P2; Satterfield et al., 1994). Do these differences show up as an increase in the size of the MMN (Satterfield et al., 1988)? Lastly are the earlier ERP components in the difference waveform in any sense precursors of later ERP changes? The answers should throw light on the contribution of elementary components of selective perceptual processing to more overt problems of children with attentional impairments.

\section{Methods}

\subsection{Subjects}

Twelve consecutive admissions with a primary DSM-III-R diagnosis from two clinicians of attention deficit disorder with/without hyperactivity (314.01 ( $\mathrm{n}=$ $6), 314.00(\mathrm{n}=6))$ made up the medication-free attention-deficit group (ADHD; age range 7.5-13.5 y; Table 1). As inpatients they may be regarded as 
severely disturbed. Such a group was selected not to be representative of the usual outpatient presentations but to ensure that core aspects of the diagnosis were present. Additional disorders concerned affect/fear (313, $\mathrm{n}=5$ plus 2 cases of enuresis or encoporesis), coordination (315, $\mathrm{n}=3$ ) and 5 cases with degrees of conduct problems. Patients were not included if the dominant problem diagnosed was not one of attention deficit or the IQ $<70$. Brief Conner's parent-teacher assessments were given to the parents and one of the ward staff. The latter gave consistently lower scores than might be expected from the usual parent-teacher assessments as ward staff are exposed daily to severe childhood problems (Table 1, with other patient data). But there was no overlap with the scores for the healthy group. The proportion of recording trials rejected due to artefact is also a measure of their restlessness (Table 1).

Young healthy children (controls, age range 8.2-12.9 y) were selected from a pool being tested in a developmental study (Oades et al., 1996) to match pairwise the ADHD children for age within 9 months (IQ > 70). They were reported free of psychiatric illness requiring consultation (past or present), a history of organic disorder and medication. The brief Conner's ratings by the parents are not directly comparable with those from the patients, but that there was no overlap of the scores indicates an absence of relevant problems in this group. All scores were well below the usual 1.5 criterion (Iaboni, Douglas \& Baker, 1995).

A comparison group of 10 children with Tourette-like symptoms was recruited to assist discrimination of the specificity of ERP changes to ADHD-like symptoms or dominant diagnosis (TS; 4 were inpatients, age range 8.2-15.2 years). With two exceptions they were not severely ill (tic severity/frequency ratings averaged 2. U1.7 on a scale of 14, derived from part of the Tourette syndrome global assessment scale; Harcherik, Leckman, Detlor \& Cohen, 1984); 5 had a primary diagnosis of multiple tics (307.22) and 5 Tourette syndrome (307.23). The similarity of the
Conner's rating scores with those from the ADHD group shows that ADHD symptoms were often present, if of secondary importance. Exclusion criteria were like the ADHD group as long as tic problems were the major problem diagnosed. Six patients were free of medic ation at testing, 2 received pimozide (1$1.5 \mathrm{mg} / \mathrm{d})$ and 2 tiapride (200-300 mg/d).

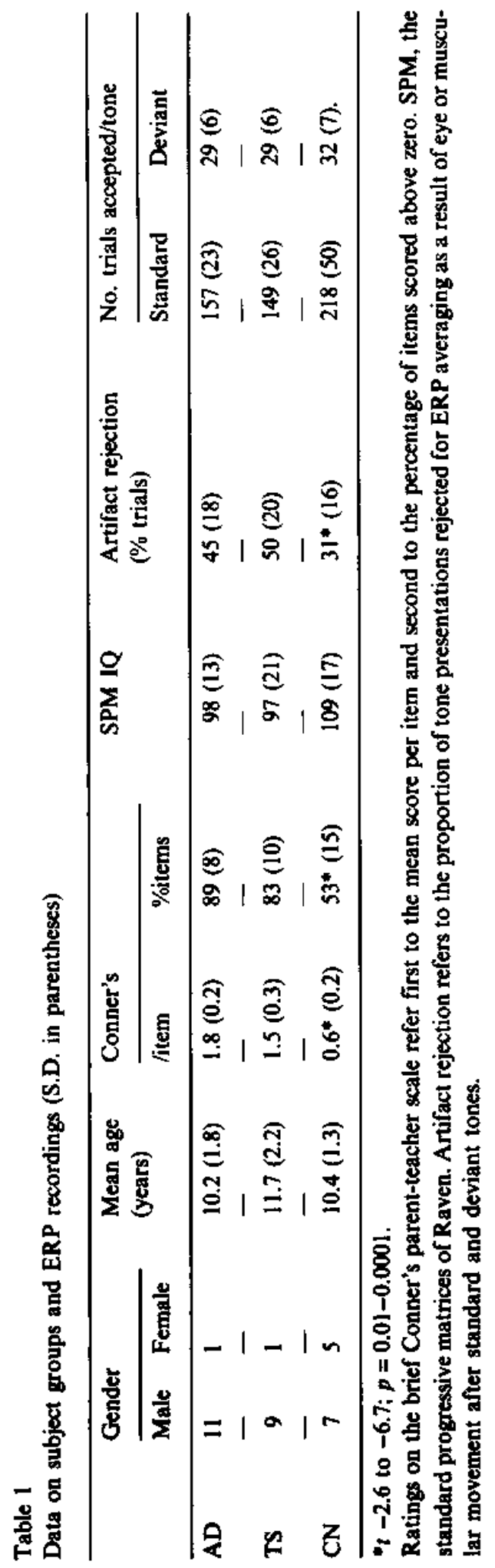


Groups did not differ significantly on performance IQ. Controls and ADHD groups were pair-wise matched for age and for Tanner ratings of maturity. TS and ADHD groups were matched for gender. From the sample available it was not possible to closely match controls and ADHD groups for both age and gender. It was considered more important to match for developmental indices. A review of the recordings for all 9 male and 8 female healthy children studied showed no gender differences that approached conventional levels of significance (amplitude maxima for $\mathrm{N} 1 \mathrm{t} \mathrm{t}=$ $0.48, p=0.64$; for $\mathrm{P} 2$ : $\mathrm{t}=1.29, \mathrm{p}=$ 0.22 ; for $\mathrm{P} 3$ : $\mathrm{t}=1.67, \mathrm{p}=0.26$; for MMN: $\mathrm{t}=0.40, \mathrm{p}=0.7)$. These pilot results were replicated in the control group (e.g., $M M N$ : $t=0.44, p=0.67$ ). This confirms reports that there are no gender differences in ERP amplitude in children for components from the mid- to the long latency range (Kraus, Smith, Reed, Stein 8c Cartee, 1985; Martin, Barajas, Fernandez \& Torres, 1988) as have been reported for adults (Deldin, Duncan \& Miller, 1994).

Testing followed (a) approval of the protocol by the management of the psychiatry clinics, (b) agreement of the therapists and nursing staff to the tests in principle and the time-point in each individual case and (c) the cooperation, understanding and consent of the child and the legally responsible adult.

\subsection{Recording procedure}

Tones from a gate-function-generator (Exact) were played binaurally over DT 48 earphones (Bayer Dynamics). Hearing thresholds were measured just before recording (Audio-Med $\mathrm{BCA} 3$ ) and if leftright ratios varied by $>5 \mathrm{~dB}$, levels were adjusted accordingly. A Bernoulli sequence of one hundred $0.8,1.4$ and $2.0 \mathrm{KHz}$ tones per trial-block were presented (65 dBSL: $p=70,15$ and $15 \%$, respectively; rise $/$ fall time $=10 \mathrm{~ms}$, duration $=50 \mathrm{~ms}$, stimulus onset asynchrony $=1.2-1.7 \mathrm{~s}$ ).

Subjects sat comfortably in an electrically-isolated, sound-attenuated, air-conditioned room with an adult seated to the side and behind. They were encouraged to fixate a small cross $1.5 \mathrm{~m}$ away on the wall to reduce eye-movement during recordings. They were told that they had nothing to do on the first 2-3 runs which were to familiarize them with the procedure and allow the experimenter to obtain a baseline recording. Rata from 19 sites (Electrocap, 10:20 system) using linked ear reference, Fpz and $\mathrm{Oz}$ as separate ground electrodes (as required by the Siemens EEG 21) with impedance $\sim 2 \mathrm{~K} \Omega$ were sampled at $250 \mathrm{~Hz}$ for $1024 \mathrm{~ms}$ (including $50 \mathrm{~ms}$ pre-trigger time) and amplified by $12 \mathrm{~K}$ using a band pass 0.3 to $70 \mathrm{~Hz}$. The sampling rate and the normalization of data reduced problems of aliasing and hardware induced delays in the latency analysis (Pivik, Broughton, Coppola, Davidson, Fox \& Nuwer, 1993).

\subsection{ERP measures and statistical methods \\ Data were evaluated at F7, F3, Fz, F4,} F8; C3, Cz, C4; P3, Pz, P4; T3, T4, T5, T6 and along with data from Fp1, Fp2, 01 and 02 formed a $5 \times 5$ grid for the topographic maps. These used a horizontal and vertical linear interpolation algorithm to establish a $180 \times 180$ point matrix. Trials with overt eye or muscular movement were rejected if the EOG exceeded $65 \mu \mathrm{V}$ above the eye. Peak amplitude and latency for 5 components were evaluated after the standard (0.8 $\mathrm{KHz})$, the high $(2.0 \mathrm{KHz})$ and the low deviants $(1.4 \mathrm{KHz})$. Then 5 peaks were similarly evaluated in the difference waveform (2.0 minus $0.8 \mathrm{KHz})$. The P1/P1-like peak was the largest positivegoing dip prior to the $\mathrm{N} 1$ (30-100 ms, difference waveform 20-120 ms). N1/ N1-like component was the earliest large negative peak (80-140 ms, difference waveform 60-180 ms). The P2/P2-like component was the largest positive postN1 ERP preceding N2 (120-240 ms in all waves). N2/MMN was the largest negative peak after P2(-like) and before P3(-like) deflections (150-300 ms). The P3/P3-like peak was the largest post-P2like positive component (240-540 ms: see details in Oades et al., 1995a,b).

Data following each tone were normalized separately by vector analysis (i.e., for each subject the mean of each component measure at each site was divided by the square root of the sum of the squared mean measures for the 15 recording sites). This tests for the potential independent effect of each tone, 
corrects for inhomogeneity in the raw data, multiplicative effects on ERPs of changes of source strength in ANOVA and anomalies arising in other normalization methods by taking account of the variance at all sites (McCarthy \& Wood, 1985; Naumann, Huber, Maier, Plihal, Wustmans, Diedrich \& Bartussek, 1992).

Our aim centred on the group-specific topography of the ERP measures and the influence of tone. Three-way MANOVAs were conducted for 3 subject groups, with 3 tones at 15 electrode sites with repeated measures. Main site effects and site interactions (group and tone) are reported following Greenhouse-Geisser epsilon correction for SPSS site-averaged test results after using Hotelling's T2 test as an assessment of potential betweenmeasure differences (Faux \& McCarley, 1990: appendix available on request). A multivariate analysis with site as a within-subjects factor was used as a precaution against between-subject variability.

Interpretation of the interactions was set in the context of the main effects obtained with a 2-way ANOVA for group and tone at $\mathrm{Cz}$ performed on the raw data. These results are described in the first part of the results section; insignificant interactions $(p>0.1)$ are not reported. The use of the terms 'tendency, trend and tend' refers to a statistical significance of $5-10 \%$ or where siteaveraged and Hotelling's tests gave contradictory evidence of significance. For the difference waveform a 2-way MANOVA was conducted for 3 subject groups at 15 sites with repeated measures, separately for each measure.

To determine where the differences lay, significant site effects were followed by paired Student t-tests for 6 selected comparisons between anterior/posterior sites (F7, Fz, F8/T5, Pz, T6) and left/ right sites (F7, T3, T5/F8, T4, T6). Even though paired comparisons were used to guard against an excessive number of comparisons, alpha was corrected according to the Bonferroni procedure as follows: $1 \%$ for comparisons after main site effects, $0.5 / 0.2 \%$ for 2 -way and $0.1 \%$ after 3-way interactions. Significant interactions were followed by one-way ANOVA or conservative Scheffe tests
(5\% level).

\section{Results}

3.1 ERPs - raw data at $\mathrm{Cz}$

There were no group PI amplitude or latency differences at $\mathrm{C} z$, but in the difference waveform latencies for Pl-like deflections were longer in the TS group (Cz; controls 68 ms, ADHD 57 ms, TS 90 ms, SD. 16; Scheffe $\mathrm{p}<0.05$; Table 2, Fig. 1 and 2). There were no N1 or N1like (difference waveform) amplitude differences, but N1 latencies in ADHD patients continued the trend of being shorter than in the other groups (by 5$7 \%)$.

Mean P2 maxima were more than twice as high in the ADHD and TS groups than in the controls (controls $2.9 \mu \mathrm{V}$, ADHD $5.7 \mu \mathrm{V}$, TS $7.1 \mu \mathrm{V}$, S.D. 4.1; Scheffe $p<0.05$; Fig. 1). (There was no interaction with the type of tone but responses to deviant tones augmented by a third in controls while showing no change in the patients). P2 latencies were shorter in the ADHD and TS groups than in the controls (controls vs. ADHD, Scheffe $p<0.05$ Fig. 3, bottom). No significant effects were recorded for peaks in this latency range in the difference waveform.

There were no effects of group or tone on N2 amplitude; but N2 latencies were longest in the TS group (controls 284 ms, ADHD 262 ms, TS 294 ms, SD. 46; (Scheffe $\mathrm{p}<0.05)$ ). There were no group effects for MMN (difference waveform) amplitude or latency.

P3 responses were variable but there was a significant effect of tone showing that peak amplitude increased with tonefrequency in each group (for rarity, Scheffe $p<0.05 ;$ Fig. 1). Latencies tended to be shorter after the deviant tones in all groups. In the difference waveform there were no effects for latepositivity measured at $\mathrm{Cz}$.

\subsection{ERPs - topography of normalized data}

All P1 maxima were frontal (In the raw data they were about twice the amplitudes recorded at posterior sites; e.g., $\mathrm{Fz}$, across tones, controls $2.0 \mu \mathrm{V}, \mathrm{ADHD}$ $1.9 \mu \mathrm{V}$, TS $2.6 \mu \mathrm{V}$, S.D. $2.3 ; \mathrm{t}=3.8, \mathrm{p}=$ 0.0001 ; Fig. 1.) But all midline latencies were shorter at posterior than frontal 


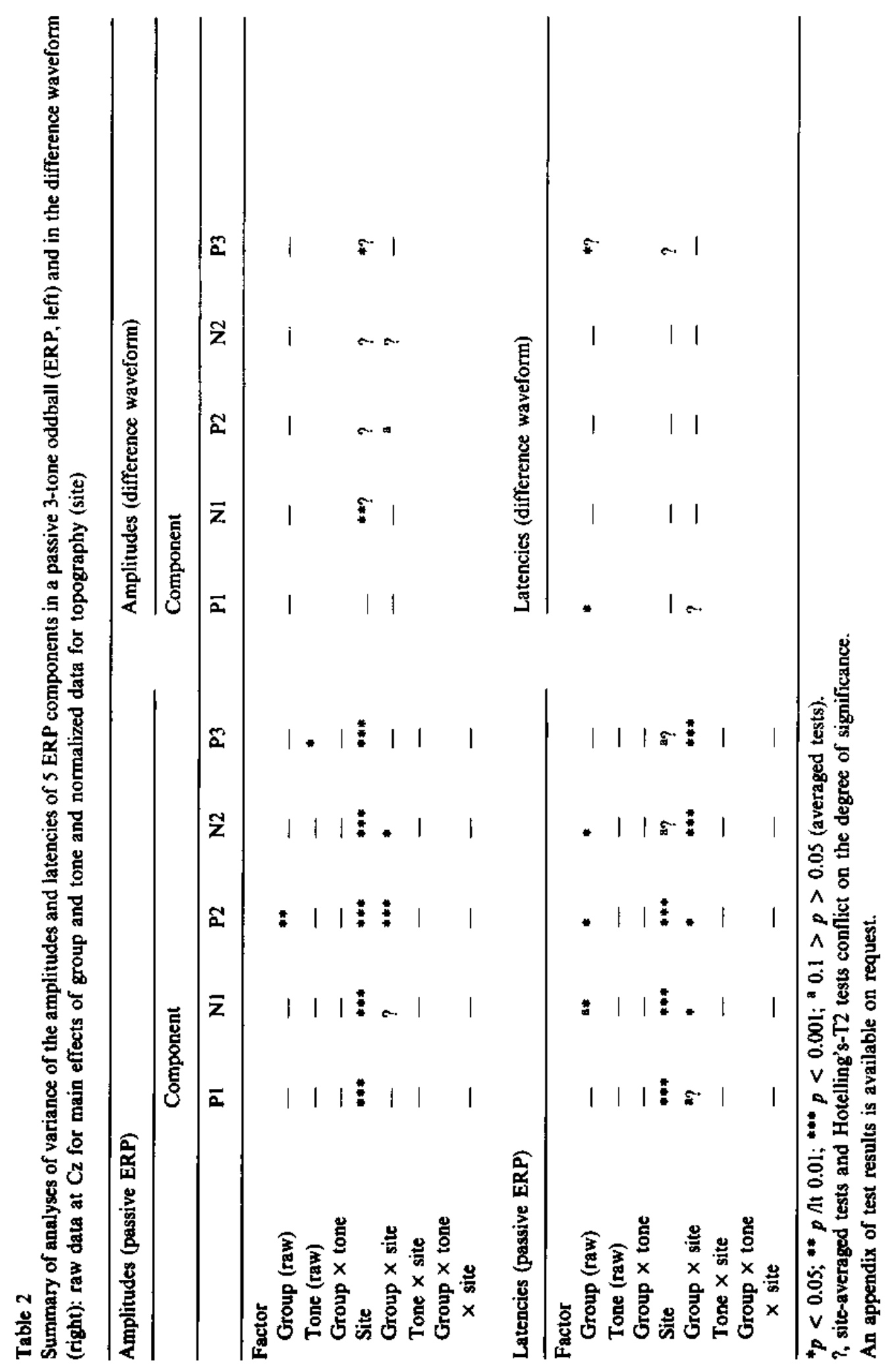


Fig. 1. Grand mean ERP waveforms $\mu \mathrm{V}$ ) after each of the 3 tones are shown for 3 subject groups (healthy children, CN, solid line; those with attention-deficit, ADHD, dashed line; or Tourette/tic symptoms, TS, dotted line) at anterior (F7, Fz, F8) and posterior sites (T5, Pz, T6) for 500 ms; insets show the EOG records - upper panel: $0.8 \mathrm{KHz}$ (standard); lower panel: $2.0 \mathrm{KHz}$ (high deviant).
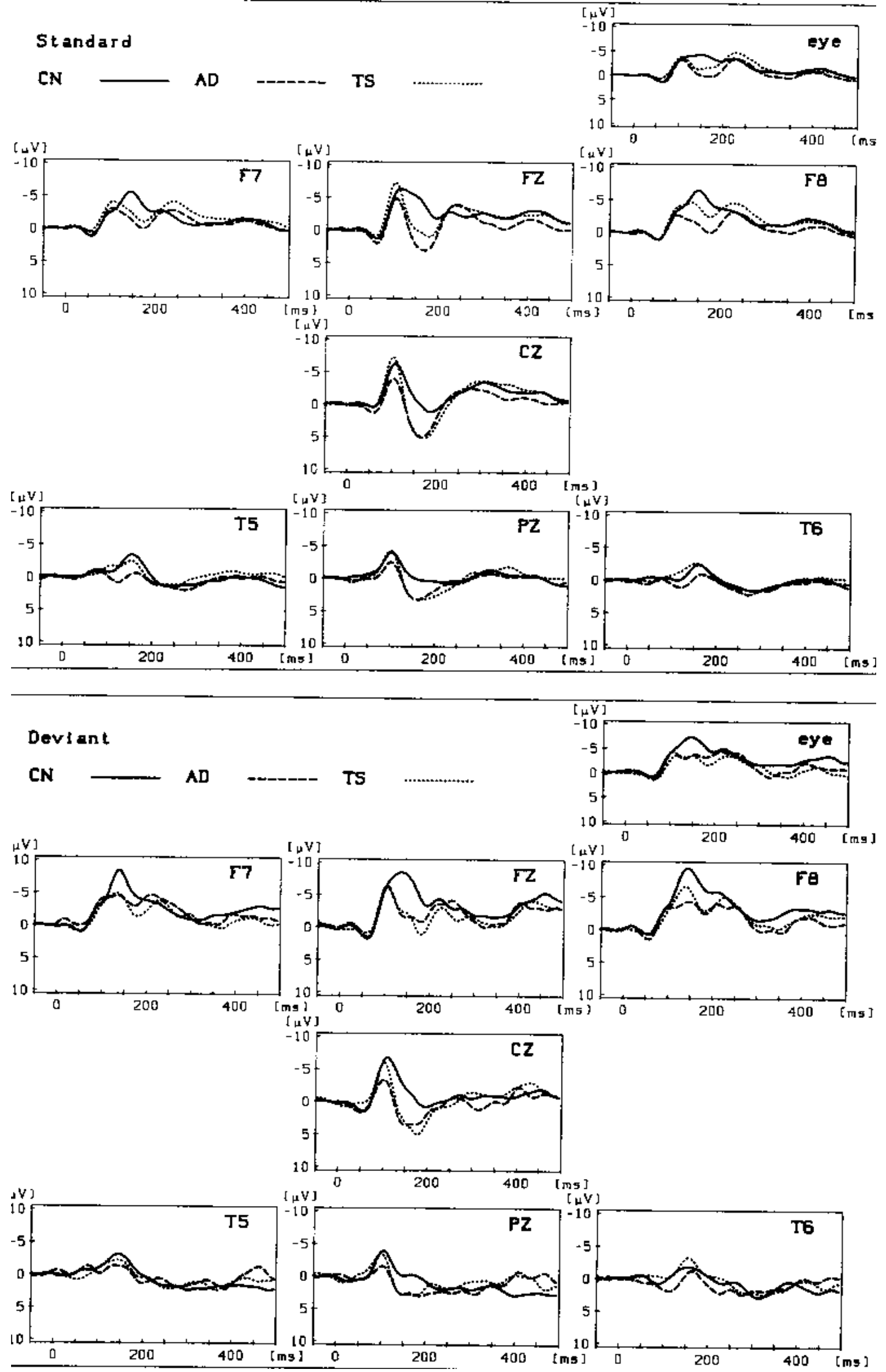
Fig. 2. Grand mean difference waveform (deviant minus standard tone) for 3 subject groups (see Fig. 1 legend) at anterior (F7, Fz, F8) and posterior sites T5, Pz, T6) for $500 \mathrm{~ms}$ (insets show EOG records); $\mathrm{CN}=$ solid line, $\mathrm{ADHD}=$ dashed line, $\mathrm{TS}=$ dotted line

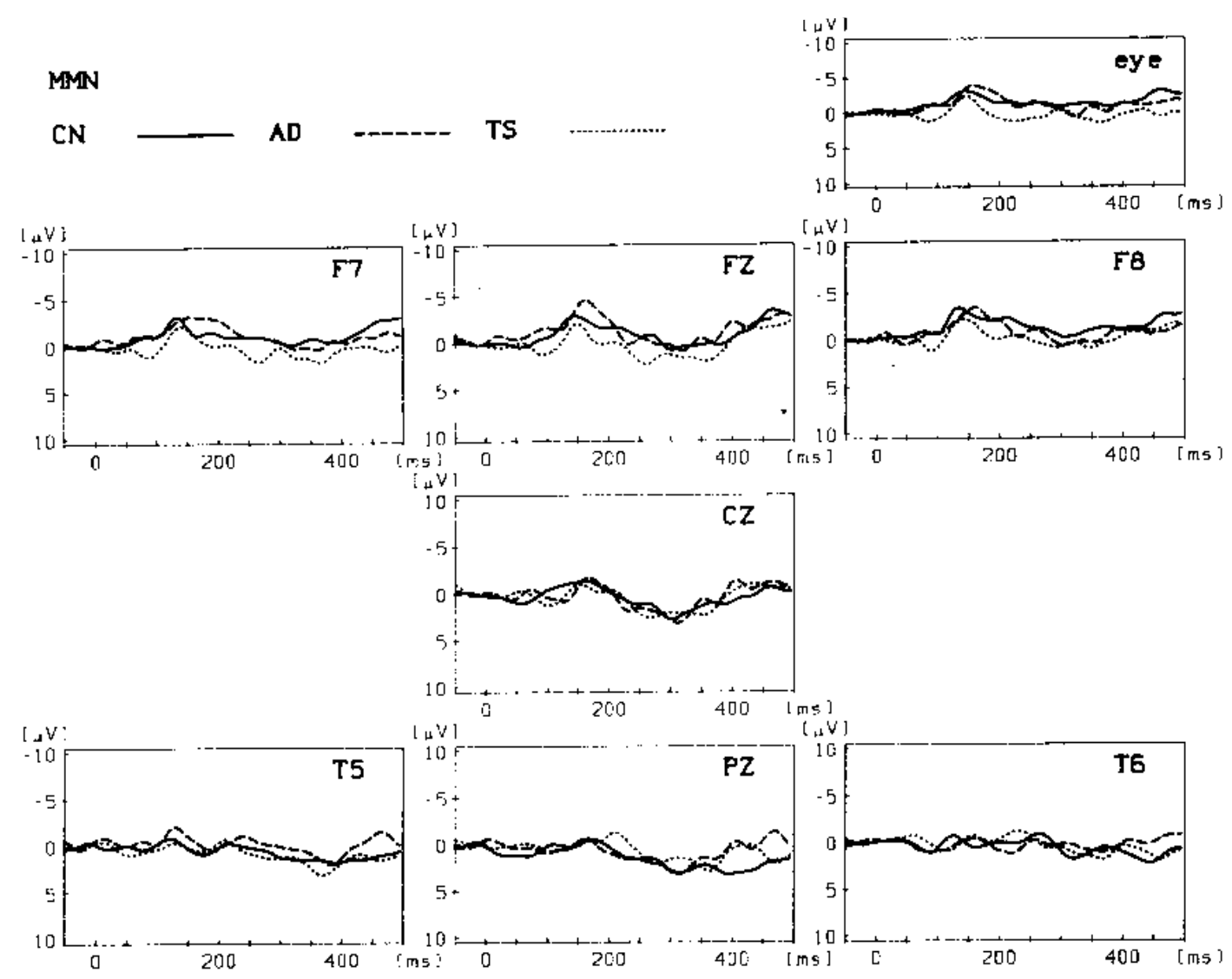

sites $(t=4.2, p=0.0001$ : across tones, $\mathrm{Fz} / \mathrm{Pz}$, controls 59/55 ms, ADHD 64/52 ms, TS 57/49 ms, S.D. 9).

Tendencies for longer PI latencies at right posterior versus frontal sites in the controls and ADHD groups ( $t=-2$ to $3.1, p=0.06-0.004)$ and at right versus left temporal sites $(t=-2.1$ to $-2.9, p=$ $0.04-0.007)$ were not seen in the TS group (T5, ADHD $<T S$, Scheffe $p<0.05$ ). In the difference waveform patients did not show the shorter left vs. right frontal latencies for P1-like positivity seen in the controls group $(t=-44.4, p=0.001)$.

N1 maxima were frontal with no group differences $(t=-3.5$ to $-9.2, p=$ $0.002-0.0001$ ). Away from these loci ADHD and control subjects had smaller peaks on the right $(\mathrm{t}=-2.5$ to $-3.4, \mathrm{p}=$ 0.018-0.002); the smallest tended to be in the ADHD group (P3/P4 controls -4.5/$5.0 \mu \mathrm{V}$, ADHD $-3.3 /-2.3 \mu \mathrm{V}$, TS -4.3/-4.0 $\mu \mathrm{V}$, S.D. 2.4; Scheffe $\mathrm{p}=0.06$; Fig. 1).

In the midline $\mathrm{N} 1$ latencies were shortest posteriorly in all groups ( $\mathrm{Fz} / \mathrm{Pz}$; controls 140/107 ms, ADHD 116/101 ms, TS $126 / 104 \mathrm{~ms}, \mathrm{~S} . D .16 ; \mathrm{t}=2.7-$ 6.9, $\mathrm{p}=0.013-0.0001$ ) and, like $\mathrm{P} 1$, more so on the left in the ADHD group (Scheffe $p<0.05$ ). In the difference waveform $\mathrm{N} 1$-like maxima were frontal ( $\mathrm{t}$ $=-2.5$ to $-4.1, p=0.019-0.0001$ ) with no group differences for amplitude or latency (Fig. 2).

P2 maxima were centro-parietal at lateral and midline sites (versus frontal sites, $\mathrm{t}=-2.2$ to $-9.0, \mathrm{p}=0.03-0.0001$ ). Fronto-central peaks were much larger in the patients than in the controls, but this reversed at postero-lateral sites T5 and T6 (TS < controls, all effects Scheffe $p<$ 0.05; see patients' anterior positivity shift, Fig. 3). The TS group showed a left bias increasing posteriorly (t 2.1-2.8, $\mathrm{p}$ $=0.05-0.008)$. Latencies were shorter at centro-parietal sites $(t=2.3, p=0.03$ ) with patients showing shorter values than the control (Scheffe $p<0.05$; Fig. 3 , right). 
Fig. 3. (Top) Topography of normalized, mean stimulus-elicited P2 amplitude over the skull after 3 tones (anterior sites uppermost in each map). Vertical columns show topographic schemata after the standard $0.8 \mathrm{KHz}$ and deviant $1.4+2.0 \mathrm{KHz}$ tones and the P2-like component in the difference waveform (labelled 'MMN': deviant minus standard). Horizontal rows show the 3 subject groups (healthy children, CN; those with attention-deficit, ADHD; or Tourette/tic symptoms, TS). (Bottom) A similar topographic representation of mean P2 latency comparisons (ms) over the skull (anterior up) in the 3 groups. These are shown from left $(\mathrm{L})$ to right $(\mathrm{R})$, with the vertex in the middle, for the standard/ deviant tones (standard deviation range on the right).

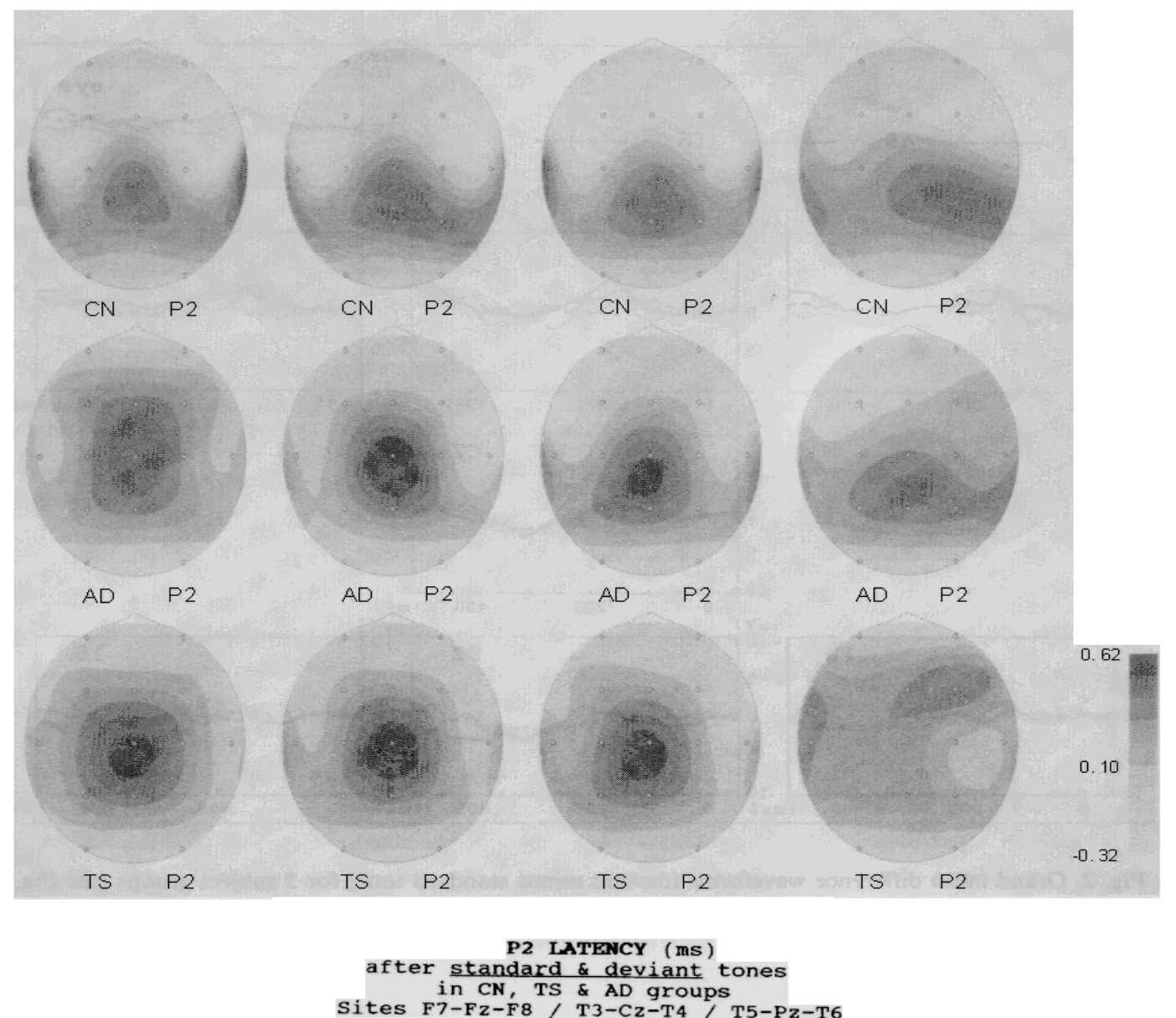

sites $\mathrm{F} 7-\mathrm{Fz}-\mathrm{F} 8 / \mathrm{T} 3-\mathrm{Cz}-\mathrm{T} 4 / \mathrm{T} 5-\mathrm{Pz}-\mathrm{T} 6$

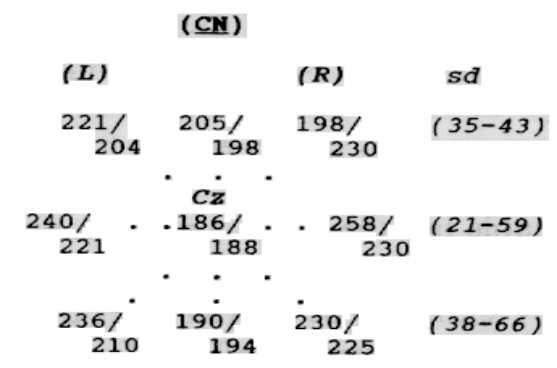

(TS)

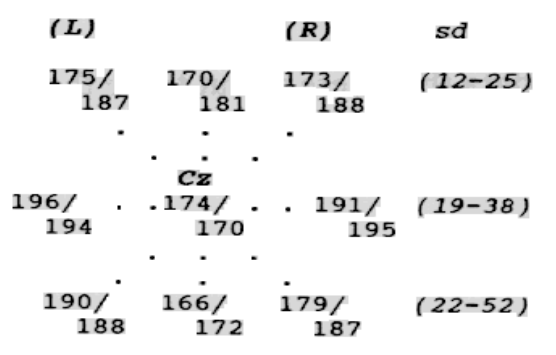

(AD)

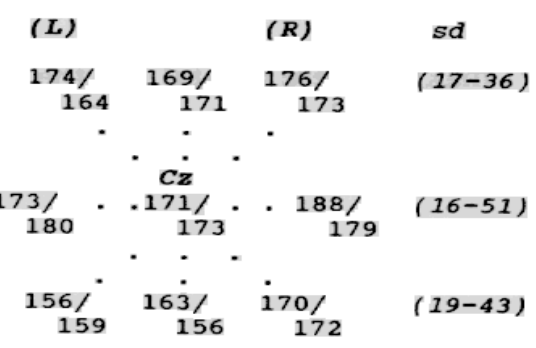


Fig. 4. (Top) Topography of normalized, mean stimulus-elicited N2 amplitude over the skull after 3 tones (anterior sites uppermost in each map). Vertical columns show topographic schemata after the standard $0.8 \mathrm{KHz}$ and deviant $1.4+2.0 \mathrm{KHz}$ tones and the MMN in the difference waveform (deviant minus standard). Horizontal rows show the 3 subject groups (healthy children, CN, those with attention-deficit, ADHD, or Tourette/Tic symptoms, TS). (Bottom) A similar topographic representation of mean N2 latency comparisons (ms) over the skull (anterior up) in the 3 groups. These are shown from left $(\mathrm{L})$ to right $(\mathrm{R})$, with the vertex in the middle, for the standard/deviant tones (standard deviation range on the right).

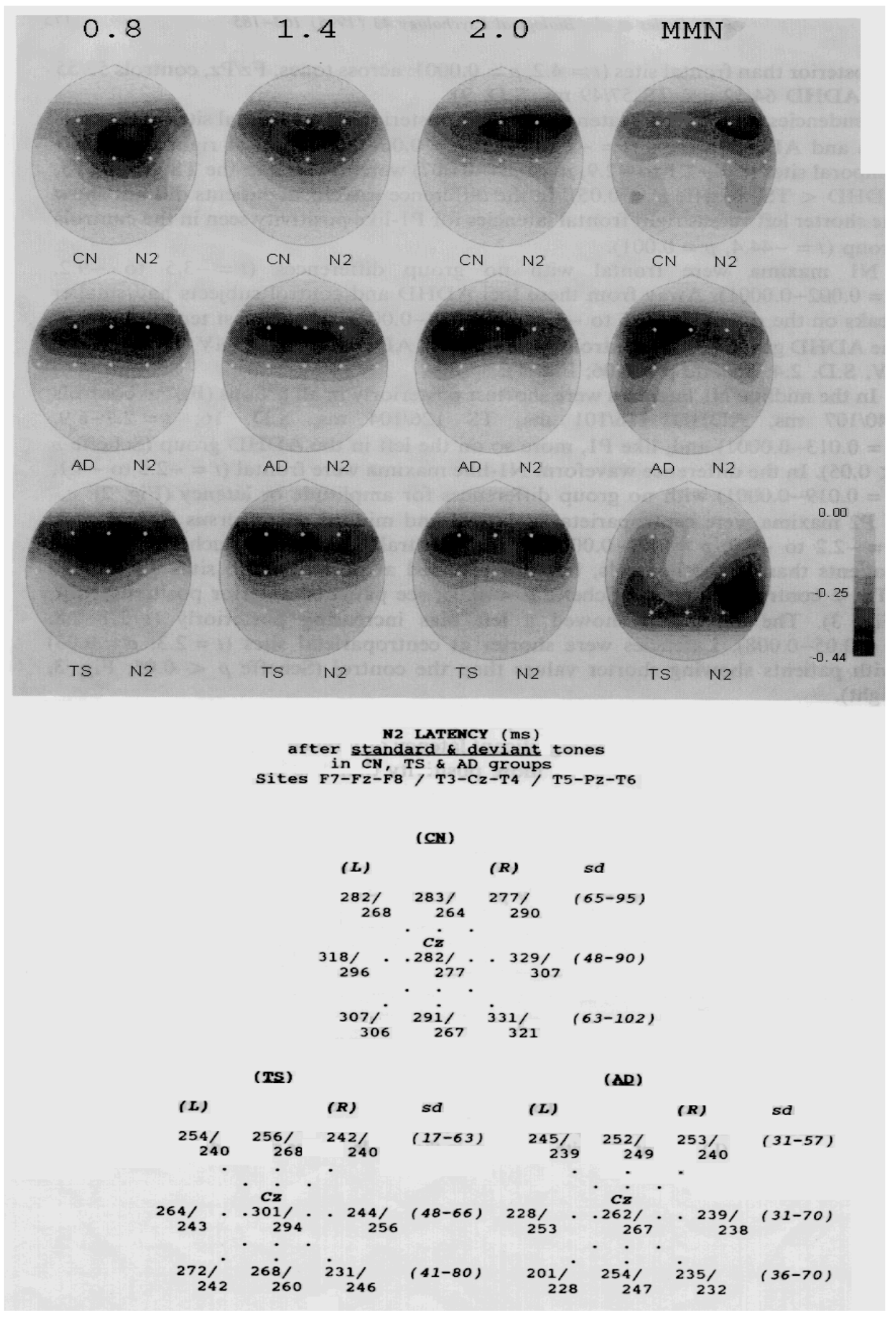


Fig. 5. (Top) Topography of normalized, mean stimulus-elicited P3 amplitude over the skull after 3 tones (anterior sites uppermost in each map). Vertical columns show topographic schemata after the standard $0.8 \mathrm{KHZ}$ and deviant $1.4+2.0 \mathrm{KHZ}$ tones and the P3-like component in the difference waveform (labelled 'MMN': deviant minus standard). Horizontal rows show the 3 subject groups (healthy children, CN; those with attention-deficit, ADHD, or Tourette/Tic symptoms, TS). (Bottom). A similar topographic representation of mean P3 latency comparisons (ms) over the skull (anterior up) in the 3 groups. These are shown in each schema from left $(\mathrm{L})$ to right $(\mathrm{R})$, with the vertex in the middle, for the standard/deviant tones in the passive presentation in the left column and for the P3-like component in the difference-wave (difference waveform, 'MMN') in the right column (SD range on the right).




In the difference waveform P2-like peak maxima were parietal ( $t=-2.2$ to 3.0, $p=0.03-0.006$; Fig. 3) without significant latency differences. Yet the TS group was again unusual in tending to show more positivity than the others over frontal but less positivity over right anterior temporal sites (controls/TS amplitude at: $\mathrm{Fz},-0.4 /+1.9 \mu \mathrm{V} ; \mathrm{C} 4$, $+1.5 /+0.6 \mu \mathrm{V} ; \mathrm{Pz},+1.5 /+1.5 \mu \mathrm{V} ;$ S.D. 2.2).

N2 maxima were localized over lateral and midline frontal sites ( $t=-5.2$ to 9.8, $\mathrm{p}=0.0001)$. The ADHD group showed a sharper drop-off of negativity away from these sites $(\mathrm{Fz} / \mathrm{Pz}$; controls 5.4/-1.9 $\mu \mathrm{V}$, ADHD -6.5/-1.2 $\mu \mathrm{V}$, TS 6.4/-2.5 $\mu \mathrm{V}$, S.D. 2.9; Fig. 4). For the control group latencies were longer away from fronto-central sites, but both patient groups had much shorter latencies on the right (e.g., Fz/T4: controls $278 / 316 \mathrm{~ms}$, ADHD 250/237 ms, TS 264/248 ms, S.D. 50; T4 and T6: Scheffe $p<0.05$; Fig. 4, right).

ADHD patients had marked MMN frontal maxima, with a left-sided bias ( $t$ $=-3.8, p=0.003$ ) that contrasted with the right bias in the control group $=-1.8$ $\mathrm{p}=0.097$ : controls $-3.1 \mu \mathrm{V}$, ADHD -5.0 $\mu \mathrm{V}$, TS $-1.1 \mu \mathrm{V}$, S.D. 3.1). TS patients tended to show posterior maxima (Fig. 4, Table 2).

P3 peaks were localized parietally $(t=$ -7.2 to $-9.4, p=0.0001)$. The effect was least marked in TS patients $(t=-2.6$ to 3.7, $\mathrm{p}=0.01-0.001$ ). However, there was a tendency for larger values on the right in the controls and TS vs. the ADHD groups (Scheffe $\mathrm{p}<0.1$; Fig. 5) as we have reported for young healthy adults (Oades et al., 1995b). In controls latencies tended to be shorter for the frontal versus the posterior component $(t=-2$, $p=0.05)$, recalling the subcomponents usually identified in active task conditions. But in patients, especially the TS group, the latency shortened posteriorly, reaching an extreme on the right (T6: Scheffe $p<0.05$; Fig. 5, right).

Late frontal positivity in the difference waveform tended to be larger in TS than in the other groups (controls $2.9 \mu \mathrm{V}$, ADHD $3.4 \mu \mathrm{V}$, TS $4.5 \mu \mathrm{V}$, S.D. 3.8). Nonetheless peak maxima were posterior in all groups, both at lateral and midline sites $(t=-2.3$ to $-2.7, p=0.028-0.012$; Fig. 5) with no lateralization effects. Latencies, as in the stimulus-elicited waveforms, tended to be longer posteriorly in the controls (right, $\mathrm{t}=$ $3.1, p=0.01$ ) but frontally in the ADHD group midline, $\mathrm{t}=2.4, \mathrm{p}=0.03$; Fig. 5, right).

\section{Discussion}

\subsection{Main results}

The main findings of interest were as follows. (a) Neither the type of tone nor the psychopathology affected early ERP amplitude (P1,N1), but the ADHD group were already processing information faster, particularly on the left. (b) Independent of tone type, the P2 amplitude was doubled in patients and the locus shifted anterior of the centroparietal maximum recorded in controls $($ ADHD < TS). An increase of P2 amplitude to increasing tone frequency was more evident in controls than patient groups. (c) Despite frontal N2 maxima in each group and frontal MMN maxima in controls and ADHD groups, MMN was often more evident at posterior than anterior sites in the TS patients. (d) In ADHD patients MMN, unlike the others, showed a left rather than a right bias. (e) A right posterior bias for P3 peaks in the control group was not seen in ADHD patients. (f) Peak size related significantly to tone type (pitch, rarity) only for the P3 component. Likewise only P3 latencies were sensitive to tone (shorter to deviant tones). However P3 latencies, after single tones or in the difference waveform, were not shorter over frontal versus parietal sites in the ADHD group as in the others.

\subsection{Latencies and speed of processing}

Peak latencies, as measures of the speed of processing were shorter in the ADHD and TS groups from the start (50 ms post-stimulus). But, interestingly for ADHD patients, they remained about lo$20 \%$ shorter for all components while for TS patients the latencies for later components normalized. In accordance with our hypothesis in the introduction this latter feature supports the contention that ADHD symptoms in TS patients may be adventitious or acquired rather than a trait within the syndrome. 
Often ERP latencies in the ADHD and TS groups did not show the normal antero-posterior (e.g., P3) or different lateralized patterns (e.g., N2). This suggests less heterogonic development of the mediating brain structures than is usual for this age group. For example the latencies of patients were often shorter on the left for earlier components $(P 1, N 1)$ then shorter on the right for later ones (N2, P3). As we are talking about latencies, the developmental delay is likely to refer to the pathways of communication between structures rather than the maturity of the structures themselves. Benes et al. (1994) noted that while brain weight increases by less than $10 \%$, myelination nearly doubles for this age group.

Earlier reports of prolonged P3 latencies in ADHD children after target or novel stimuli in visual or auditory modalities (Picton et al., 1984) were not confirmed. But our work agrees more with that of Robaey, Breton, Dugas and Renault (1992) who reported shorter visual P3 latencies in ADHD children and interpreted this in terms of their relatively enhanceed automatic processing. The idea of speeded processing would be consistent both with the existence of fewer checks on information flow (more automatic/less controlled) and the possibility of fewer fibres for carrying out such 'checks' on associative processes. Here we refer to evidence for a reduced mid- rostral callosum and fewer frontal lobe fibres in MRI studies of older ADHD patients (Giedd, Castellanos, Casey, Kozuch, King, Hamburger \& Rapoport, 1994; Hynd, Semrud-Clikeman, Lorys, Novey, Eliopoulos \& Lyytinen, 1991).

\subsection{Amplitudes and regional function}

Most authors have not found differences of ERP response to non-targets in the groups studied here (e.g., Loiselle et al., 1980). But some decrease (Satterfield \& Braley, 1977) or no change of N2 size has been described (Satterfield et al., 1988). P3 amplitudes have also been reported to decrease as latency increaseed (Picton et al., 1984). The contrast of these findings with the absence of group effects for the ampli-tude of the later components reported here is most likely explained by the absence of a task condition requiring the focusing of attention on a target stimulus.

However increases of P2 amplitude to visual (Robaey et al., 1992) and auditory stimuli, particularly if the children were hyperactive as well as attention impaired, have been described (Holcomb et al., 1986; Ritter, Kelso, Kutas \& Shiffrin, 1984). Our results, as predicted, replicate these findings for stimulus processing in the absence of task requirements. An interpretation of this impressive increase is proposed along the lines suggested in the introduction. The P2 component reflects inhibitory processes (Hegerl \& Juckel, 1993; Schupp et al., 1994) normally associated with the end of the allocation of process-ing channels indexed by $\mathrm{N} 1$. If this limitation is expressed more strongly, then other stimuli competing for these channels will have to elicit more excitation to succeed. The prediction is that normal persons are more likely to allocate processing capacity between relatively unimportant stimuli (modest excitation): but if P2 is large, as in the case of ADHD children, the relatively unimportant stimulus is more likely to be processed without competition to the stage when it elicits a response. This interpretation is consistent with the explanation of impulsive cognitive styles described by Sonuga-Barke et al. (1994) and Schachar et al. (1995) and could be tested in future ERP studies.

$\begin{aligned} & \text { Smaller components in difference } \\ & \text { derived from rarget }\end{aligned}$
waveforms hemen reported
processing have been
(Satterfield et al., 1994). In our study
frontal MMN reflecting non-target
processing was larger in our ADHD
patients, but not significantly so. In a
similar vein, the preliminary work of
Winsberg et al. (1993) reported enlarged
frontal MMN in ADHD children, albeit
with a longer latency. They also reported
a significant component in the N1
latency range of this waveform. These
results offer some support to our anal-
ysis; the modest differences are
probably attributable to the concen-
tration on the allocation of attention to
targets (in the two stimulus oddball
paradigm). Except for the work of
Satterfield on discrimin-ation, ERP
topography has been largely neglected.

In ADHD patients the $\mathrm{P} 2$ and the 
N2/MMN showed a frontal shift or emphasis, respectively, suggesting atypical function in regions generating these components. The opposite polarity of these components suggests that the effect cannot be a general one of more or less excitation or inhibition, attributed to negative and positive deflections (Schupp et al., 1994). In adults the P2 and MMN components show frontocentral maxima (Oades et al., 1995a,b): using different techniques the sources of these components have been attributed to adjacent loci in the superior temporal plane of the auditory cortex (P2: Verkindt, Bertrand, Thevenet \& Pemier, 1994, MMN: Tiitinen, Alho, Huotilainen, Ilmoniemi, Simola \& Näätänen, 1993). Considering the resolution of the techniques involved, it is conceivable that the decreased metabolism and blood flow reported from tomographic studies for the frontal lobe and somatosensory cortex in ADHD could extend to auditory processing in the superior temporal gyrus (Lou, Henriksen \& Bruhn, 1984; Zametkin, Liebenauer, Fitzgerald, Ring, Minkunas, Herscovitch, Yamada \& Cohen, 1993). The presence of rightsided anomalies reported by both of these groups may be consistent with our finding MMN to be expressed on the left side in the ADHD group rather than on the right as in controls.

The results in this study counter the widespread belief that decreased P3 amplitudes are associated with most sorts of psychopathology. Here, if anything they were slightly larger than normal in the ADHD group. P3 differences in a passive oddball presentation have also been reported for schizophrenic patients (Faux, Shenton, McCarley, Tore110 \& Duffy, 1988).

However it is notable that while P3 maxima were right-biased in the controls, they were in the midline for the ADHD patients. The lateralization in the controls matches that found using the same paradigm in healthy young adults. But these same subjects showed a midline distribution during the active focused attention condition (Oades et al., 1995b). As this therefore does not seem to reflect a developmental feature, it would seem that the effort (or a related intervening variable) brought to bear on information processing during task solution is engaged by ADHD children in a non-task situation.

But as this goes against the conclusions of the broad spectrum of psychological testing of ADHD children, we propose an alternative. In their analysis of brain systems active during attentional processes, Posner and Petersen (1990) reviewed evidence that the right hemisphere is important for maintenance of a state of alertness and for sustained attention. If right hemisphere function is impaired then important contributions to information processing on the right, marked for example by P3 and MMN, may be missing. As a consequence the remaining representation of these components is recorded from the midline or the left hemisphere.

Could this feature be attributed to a developmental delay and preclude the younger ADHD subjects from making a successful discrimination? On the one hand, the larger N2/P3 peaks recorded in the ADHD group would be consistent with the c. $20 \%$ larger peaks seen in normal children 2-3 years younger (Ladish \& Polich, 1989). On the other hand, the faster latencies of early components shown by ADHD patients matches those we have found in normal children 4 years older (Oades et al., 1996). However normal 14year-old children showed shorter P3 latencies than the ADHD group here. Thus the evidence can be used to support the presence in ADHD children both of a delay in neural maturation and of a more fundamental long lasting functional impairment.

\subsection{TS versus ADHD groups - clinical implications}

ADHD patients had shorter peak latencies than healthy controls. However in TS patients, who also showed symptoms of attention deficit, only the early ERPs had shorter latencies. While TS patients did show a large P2 with an anterior shift like the ADHD group, they did not show the latter's left shift for the MMN. Uniquely the TS group showed weak frontal and strong posterior MMN.

There seem to be three aspects that are clinically relevant. The first relates to 
the apparently 'hypofrontal' function seen in the MMN of the TS group which recalls that seen in non-paranoid schizophrenics (Oades, 1995). Cognitive therapy of the sort attempted with hypofrontal schizophrenics could be adapted for younger patients and be supportive not only of their frequent poor academic performance but also in developing coping strategies for their stressful experiences (Cohen \& Leckman, 1994).

Second there is the large $\mathrm{P} 2$ response. Hegerl and Juckel (1993) recently marshalled evidence to show a certain dependence of P2 amplitude on serotonin activity. We have measured monoamine activity in 24-h urine samples from 19 ADHD patients (including those in the present study) and found serotonin metabolite levels were double control values (in preparation). If further study confirms a relationship (not noted before; Zametkin \& Rapoport, 1987), therapeutic trials of serotonergic agents may again be considered. We tentatively suggest that the explanation may lie in our subjects showing more comorbid 'internalizing' symptoms than the perhaps more usual 'externalizing' nature of conduct disorder more commonly associated with studies relating changes of catecholaminergic function with ADHD (Oades, 1987).

Such a pharmacotherapeutic strategy may be relevant to our third point. TS patients appeared to show, in addition to the unique symptoms and ERP features, considerable overlap of attention deficit symptoms and P2 increase with the ADHD group. Attention-deficit has often been noted in TS patients (Biederman, Newcome \& Sprich, 1991). That it should show up clearly in a consecutive series of admissions has implications both for their psychosocial therapy and pharmacotherapy (Bemstein \& Borchardt, 1991). Should the preliminary data on serotonergic activity receive support, this would be valuable for TS patients with ADHD symptoms where psychostimulants are contra-indicated and neuroleptic nonresponse is frequent (Kerbeshian $8 \mathrm{c}$ Burd, 1988).

\section{Acknowledgments}

We are grateful to Rita Franzka, Jutta
Haverkom and Robert Windelschmidt for help in the recordings.

\section{References}

Alaghband-Rad, J., McKetma, K., Gordon, C.T., Albus, K.E., Hanburger, SD., Rummy, J.M., Frazier, J.A., Lenane, M.C., \& Rapoport, J.L. (1995). Childhood -onset schizophrenia: the severity of premorbid course. Journal of the American Academy of Child and Adolescent Psychiatry, 34, 1273-1283.

Alain, C., Achim, A., \& Richer, F. (1993). Perceptual context and the selective attention effect on auditory event-related potentials. Psychophysiology, 30, 572580.

Renes, F.M., Turtle, M., Khan, Y., \& Farol, P. (1994). Myelination of a key relay zone in the hippocampal formation occurs in the human brain during childhood, adolescence and adulthood. Archives of General Psychiatry, 51, 477-484.

Bernstein, G.A., \& Borchardt, CM. (1991). Anxiety disorders of childhood and adolescence: a critical review. Journal of the American Academy of Child and Adolescent Psychiatry, 30, 519-532.

Biederman, J., Newcome, J., \& Sprich, S. (1991). Comorbidity of attention deficit disorder with conduct, depressive, anxiety and other disorders. American Journal of Psychiatry, 148, 564-511.

Breton, F., Ritter, W., Simson, R., \& Vaughan, H.G. (1988). The N2 component elicited by stimulus matches and multiple targets. Biological Psychology, 27, 23-44.

Cantwell, D.P., \& Baker, L. (1992). Attention deficit disorder with and without hyperactivity: a review and comparison of matched groups. Journal of the American Academy of Child and Adolescent Psychiatry, 31, 432-438.

Cohen, D.J., \& Leckman, J.F. (1994). Developmental psychopathology and neurobiology of Tourette's syndrome. Journal of the American Academy of Child and Adolescent Psychiatry, 33, 2-15.

Cook, J.R., Mausbach, T., Burd, L., Gascon, G., Patterson, B., Johnson, R.D., Hankey, R., \& Reynolds, B.W. (1993). A preliminary study of the relationship between central auditory processing disorder and attention deficit disorder. Journal of Psychiatry and Neuroscience, $18,130-131$. 
Corkum, P.V., \& Siegel, L.S. (1993). Is the continuous performance task a valuable research tool for use with attentiondeficit hyperactivity disorder? Journal of Child Psychology and Psychiatry, 34, 1217-1239.

Deldin, P.J., Duncan, C.C., \& Miller, G.A. (1994). Season, gender and P300. Biological Psychology, 39, 15-28.

Donchin, E., \& Coles, M.G.H. (1988). Is the P300 component a manifestation of context updating? Behavioral Brain Sciences, II, 351-427.

Faux, S.F., \& McCarley, R.W. (1990). Analysis of scalp voltage asymmetries using Hotelling's T2 methodology. Brain Topography, 2, 237-245.

Faux, SF., Shenton, M.E., McCarley, R.W., Torello, M., \& Duffy, F. (1988). Differentiation of schizophrenics and normal controls is enhanced by the Goodin subtraction procedure. International Journal of Neuroscience, 39, I 17- 135.

Giard, M.H., Lavikainen, J., Reinikainen, K., Perrin, F., Bertrand, O., Pemier, J., \& Näätänen, R. (1995). Separate representation of stimulus frequency, intensity and duration in auditory sensory memory: an event-related potential and dipole analysis. Journal of Cognitive Neuroscience, 7, 133- 143.

Giedd, J.N., Castellanos, F.X., Casey, B.J., Kozuch, P., King, A.C., Hamburger, SD., \& Rapoport, J.L. (1994). Quantitative morphology of the corpus callosum in attention deficit hyperactivity disorder. American Journal of Psychiatry, 151, 665-669.

Hansen, J.C., \& Hillyard, S.A. (1980). Endogenous brain potentials associated with selective auditory attention. Electroencephalography and Clinical Neurophysiology, 49, 271-290.

Hansen, J.C., \& Hillyard, S.A. (1988). The temporal dynamics of human auditory selective attention. Psychophysiology, 25, 316-329.

Harcherik, D.F., Leckman, J.F., Detlor, J., \& Cohen, D.J. (1984). A new instrument for clinical studies of Tourette's syndrome. Journal of the American Academy of Child and Adolescent Psychiatry, 23,153-160.

Hegerl, U., \& Juckel, G. (1993). Intensity dependence of auditory evoked potentials as an indicator of central serotonergic neurotransmission: a new hypothesis. Biological Psychiatry, 33, 173-187.

Holcomb, P.J., Ackerman, P.T., \& Dykman, R.A. (1986). Auditory event-related potentials in attention and readingdisabled boys. International Journal of Psychophysiology, 3, 263-213.

Hynd, G.W., Semrud-Clikeman, M., Lorys, A.R., Novey, E.S., Eliopoulos, D., \& Lyytinen, H. (1991). Corpus callosum morphology in attention-deficit hyperactivity disorder (ADHD): Morphometric analysis of MRI. Journal of Learning Disabilities, 24, 141-146.

laboni, F., Douglas, V.I., \& Baker, A.G. (1995). Effects of reward and response costs on inhibition in ADHD children. Journal of Abnormal Psychology, 104, 232-240.

Kerbeshian, J., \& Burd, L. (1988). A clinical pharmacological approach to treating Tourette syndrome in children and adolescents. Neuroscience and Biobehavioral Reviews, 12, 241-245.

Klorman, R., Salzman, L.F., Bauer, L.O., Coons, H.W., Borgstedt, A. D., \& Halpern, W.I. (1983). Effects of two doses of methylphenidate on crosssituational and borderline hyperactive children's evoked potentials. Electroencephalography and Clinical Neurophysiology. 56, 169- 185.

Kofoed, 8,. Bak, C.K., Rahn, E., \& Saermark, K. (1995). Auditory eventrelated magnetic fields in a tone-duration discrimination task. Source localization for the mismatch field and for a new component M2. Acta Neurologica Scandinavica. 91, 362-371.

Kraus, N., Smith, D.I., Reed, N.L., Stein, L.K., \& Cartee, C. (1985). Auditory middle latency response in children: effects of age and diagnostic category. Elecfroencephalography and Clinical Neurophysiology, 62, 343-351.

Ladish, C., \& Polich, 1. (1989). P300 and probability in children. Journal of Experimental Child Psychology, 48, 212-223.

Levin, H.S., Culhane, K.A., Hartmann, J., Evankovich, K., Mattson, A.J., Harward, H., Ringholz, G., Ewing-Cobbs, L., \& Fietcher, J.M. (1991). Developmental changes of performance on tests of purported frontal lobe functioning. Developmental Neuropsychology, 7, 377-395.

Loiselle, D.L., Stamm, J.S., Maitinsky, S., \& Whipple, S.C. (1980). Evoked potential 
and behavioral signs of attentive dysfunction in hyperactive boys. Psychophysiol ogy, 17, 193-201

Lou, H.C., Henriksen, L., \& Bruhn, P. (1984). Focal cerebral hypoperfusion in children with dysphasia and or attention deficit disorder. Archives of Neurology, 41, 825-829.

Martin, L., Barajas, J.J., Femandez, R., \& Torres, E. (1988). Auditory evoked potentials in well-characterized groups of children. Electroencephalography and Clinical Neurophysiology, 71, 375-381.

McCarthy, G., \& Wood, CC. (1985). Scalp distribution of event-related potentials: an ambiguity associated with analysis of variance models. Electroencephalography and Clinical Neurophysiology, 62,203208.

Näätänen, R. (1990). The role of attention in auditory information processing as revealed by event-related potentials and other brain measures of cognitive function. Behavioral Brain Sciences, 13, 201-288.

Naumann, E., Huber, C., Maier, S., Plihal, W., Wustmans, A., Diedrich, O., \& Bartussek, D. (1992). The scalp topography of P300 in the visual and auditory modalities: a comparison of three normalization methods and the control of statistical type II error. Electroencephalography and Clinical Neurophysiology, 83, 254-264.

Oades, R.D. (1987) Attention deficit disorder with hyperactivity $(A D D H)$ : the contribution of central catecholaminergic activity. Progress in Neurobiology, 29, 365-391,

Oades, R.D. (1995). Connections between the neurobiology of attention, psychotic processes and event-related potentials. In G. Karmos, M. Molnar, V. Csepe, I. Czigler, \& J.E. Desmedt (Eds.). Perspectives of event-related potential research (pp. 428-438), Electroencephalography and Clinical Neurophysiology, Suppl. 44. Amsterdam: Elsevier.

Oades, R.D., Dittmann-Balcar, A., \& Zerbin, D. (1995a). The topography of 4 subtraction ERP waveforms derived from a 3-tone auditory oddball task in healthy young adults. International Journal of Neuroscience, 81, 265-281.

Oades, R.D., Zerbin, D., \& Dittmann-Balcar, A. (1995b). The topography of eventrelated potentials in passive and active conditions of a 3-tone auditory oddball test. International Journal of Neuroscience, 81,249-264.

Oades, R.D., Dittmann-Balcar, A., \& Zerbin, D. (1996). Development and topography of auditory event-related potentials, mismatch and processing negativity from 8 to 22 years of age, Psychophysiology, in press.

Oades, R.D., Walker, M.K., Geffen, L.B., \& Stern, L.M. (1988). Event-related potentials in autistic and healthy children on an auditory choice reaction time task. International Journal of Psychophysiology, 6, 25-37.

Paavilainen, P., Tiitinen, H., Alho, K., \& Näätänen, R. (1993). Mismatch negativity to slight pitch changes outside strong attentional focus. Biological Psychology, 37, 23-41.

Pauls, D.L., Hurst, C.R., Kruger, SD., Leckman, J.F., Kidd, K., \& Cohen, D.J. (1986). Gilles de la Tourette's syndrome and attention deficit disorder: evidence against a genetic relationship. Archives of General Psychiatry, 43, 1177-1179.

Piaget, J. (1952). The origins of intelligence in children. New York International Universities Press.

Picton, T.W., Donchin, E., Ford, J., Kahneman, D, \& Norman, D. (1984). Report of panel II: the ERP and decision and memory processes. In $\mathrm{E}$. Donchin (Ed.). Cognitive psychophysiology: event-related potentials and the study of cognition (pp. 179-201). Hillsdale, NJ: Lawrence Erlbaum Associates.

Pivik, R.T., Broughton, R.J., Coppola, R., Davidson, R.J., Fox, N., Br Nuwer, M.R. (1993). Guidelines for the recording and quantitative analysis of electroencephalographic activity in research contexts. Psychophysiology, 30, 541-558.

Posner, M.I., \& Petersen, SE. (1990). The attention system of the human brain. Annual Reviews in the Neurosciences. $13,25-42$.

Ritter, W., Kelso, W., Kutas, M., \& Shiffrin, R. (1984). Report of panel III: preparatory processes. In E. Donchin (Ed.). Cognitive psychophysiology: eventrelated potentials and the study of cognition (pp. 214-263). Hillsdale, NJ: Lawrence Erlbaum Associates.

Robaey, P., Breton, F., Dugas, M., \& Renault, B. (1992). An event-related potential study of controlled and automatic processes in 6-8-year-old boys with attention deficit hyperactivity 
disorder. Electroencephalography and Clinical Neurophysiology, 82, 330-340.

Satterfield, J.H. (1973). EEG issues in children with minimal brain dysfunction. Seminars in Psychiatry, 5, 35-46.

Satterfield, J.H., \& Braley, B.W. (1977). Evoked potentials and brain maturation in hyperactive and normal children. Electroencephalography and Clinical Neurophysiology, 43, 43-51I.

Satterfield, J.H., Schell, A.M., \& Nicholas, T. (1994). Preferential processing of attended stimuli in attention-deficit hyperactivity disorder and normal boys. Psychophysiology, 31, $1-10$.

Satterfield, J.H., Schell, A.M., Nicholas, T.W., \& Backs, R.W. (1988). Topographic study of auditory event-related potentials in normal boys and boys with attention deficit disorder with hyperactivity. Psychophysiology, 25, 591-606.

Schachar, R., Tannock, R., Marriott, M., \& Logan, G. (1995). Deficient inhibitory control in attention deficit hyperactivity disorder. Journal of Abnormal Child Psychology, 23, 411-439.

Schupp, H.T., Lutzenberger, W., Rau, H., \& Birbaumer, N. (1994). Positive shifts of event-related potentials: a state of cortical disfacilitation as reflected by the startle reflex probe. Electroencephalography and Clinical Neurophysiology, 90, 135- 144.

Sonuga-Barke, E.J.S., Houlberg, K., \& Hall, M. (1994). When is 'impulsiveness' not impulsive? The case of hyperactive children's cognitive style. Journal of Child Psychology and Psychiatry, 35, 12471253.

Taylor, M.J., Voros, J.G., Logan, W.J., \& Malone, A.A. (1993). Changes in eventrelated potentials with stimulant medication in children with attention deficit hyperactivity disorder. Biological Psychology, 36, 139-156.
Tiitinen, H., Alho, K., Huotilainen, M., Ilmoniemi, R.J., Simola, J., \& Näätänen, R. (1993). Tonotopic auditory cortex and the magnetoencephalographic (MEG) equivalent of the mismatch negativity. Psychophysiology, 30, 531-540.

Treisman, A.M. (1969). Strategies and models of selective attention. Psychology Reviews, 76, 282-299.

Verbaten, M.N., Overtoom, C.C.E., Koelega, H.S., Swaab-Bamevald, H., van der Graag, R.J., Buitelaar, J.K., \& van Engeland, H. (1994). Methylphenidate influences on both early and late ERP waves of ADHD children in a continuous performance test. Journal of Abnormal Child Psychology, 22,561-578.

Verkindt, C., Bertrand, O., Thevenet, M., 8c Pemier, J. (1994). Two auditory components in the 130-230 ms range disclosed by their stimulus frequency dependence. NeuroReport, 5, I 189- 1192.

Winsberg, B.G., Javitt, D.C., Silipo, G.S., \& Doneshka, P. (1993). Mismatch negativity in hyperactive children: effects of methylphenidate. Psychopharmacol-ogy Bulletin, 29, 229-233.

Zametkin, A.J., Liebenauer, L.L., Fitzgerald, G.A., King, A.C., Minkunas, D.V., Herscovitch, P., Yamada, E.M., \& Cohen, R.M. (1993). Brain metabolism in teenagers with attention-deficit hyperactivity disorder. Archives of General Psychiatry. 50, 333-340.

Zametkin, A.J., \& Rapoport, J.L. (1987). Neurobiology of attention deficit disorder with hyperactivity: where have we come in 50 years? Journal of the American Academy of Child and Adolescent Psychiatry, 26. 616-686. 